\title{
Experimental Delayed Postischemic Spinal Cord Hypoperfusion After Aortic Cross-clamping
}

\author{
F. Follis, K. Miller, O.U. Scremin, S. Pett, R. Kessler, T. Temes and J.A. Wernly
}

\begin{abstract}
Background: As in the brain, recent evidence has suggested a defect in the microcirculation during the reperfusion period after spinal cord ischemia. This investigation was undertaken in order to delineate blood flow dynamics in the postischemic spinal cord of the rat. Methods: Male Sprague-Dawley rats underwent cross-clamping of the aorta and subclavian arteries (XC) for 11 minutes. Spinal cord blood flow (SCBF) was measured by autoradiography in the gray and white matter of cervical (Ce), thoracic (Th) and lumbar (Lu) regions during $\mathrm{XC}, 1 \mathrm{~h}, 6 \mathrm{~h}$ and $24 \mathrm{~h}(\mathrm{XC} \mathrm{n}=8,1 \mathrm{~h} \mathrm{n}=9$, $6 \mathrm{~h} \mathrm{n}=9$, and $24 \mathrm{~h} \mathrm{n}=11$, groups) after XC. Control groups underwent surgical manipulations and SCBF measurement but no XC (Sham $1, \mathrm{n}=8$ ), or clamping of the subclavian arteries only (Sham 2 , $\mathrm{n}=8$ ). Results: In Ce cord, there was no difference between SCBF of $1 \mathrm{~h}, 6 \mathrm{~h}, 24 \mathrm{~h}$ and Sham 1. In Th cord, SCBF was reduced during $\mathrm{XC}(\mathrm{P}<0.003$ vs. Sham 2$), 1 \mathrm{~h}, 6 \mathrm{~h}(\mathrm{P}<0.04$ and $\mathrm{P}<0.01$ vs. Sham 1). In Lu cord, SCBF was not detectable in XC, and depressed in $1 \mathrm{~h}(\mathrm{P}<0.003)$ and $6 \mathrm{~h}(\mathrm{P}<0.003)$. There was no difference between $24 \mathrm{~h}$ and Sham $\mathrm{I}$ in Ce, Th, and Lu cords. Conclusions: The study demonstrated a period of delayed postischemic hypoperfusion in the white and gray matter of Th and Lu cord segments lasting $6 \mathrm{~h}$ after XC. The phenomenon may play an important role in the ultimate fate of neural elements with borderline viability after ischemic injury.
\end{abstract}

\begin{abstract}
RÉSUMÉ: Hypoperfusion expérimentale retardée suite à une ischémie de la moelle épinière par clampage de l'aorte. Introduction: Des observations récentes suggèrent qu'il existe un défaut dans la microcirculation pendant la période de reperfusion après une ischémie de la moelle épinière comme c'est le cas dans le cerveau. Le but de cette étude était de définir la dynamique du flot sanguin dans la moelle épinière de rat en période post-ischémique. Méthodes: Des rats mâles Sprague-Dawley ont subi un clampage total de l'aorte et des artères sous-clavières (CA) pendant 11 minutes. Nous avons mesuré par autoradiographie le flot sanguin de la moelle épinière (FSME) dans la substance grise et la substance blanche des régions cervicale (Ce), thoracique (Th) et lombaire (Lo) pendant le CA, $1 \mathrm{~h}, 6 \mathrm{~h}$, et $24 \mathrm{~h}$ après le clampage (groupes $\mathrm{CA} \mathrm{n}=8,1 \mathrm{~h} \mathrm{n}=9,6 \mathrm{~h} n=9$ et $24 \mathrm{~h} \mathrm{n}=11$ ). Les groupes contrôles ont subi des manipulations chirurgicales et des mesures du FSME sans CA (groupe contrôle $1, n=8$ ) ou clampage des artères sous-clavières seulement (groupe contrôle $2, \mathrm{n}=8$ ). Résultats: Il n'y avait pas de différence au niveau de la moelle cervicale entre le FSME à $1 \mathrm{~h}, 6 \mathrm{~h}, 24 \mathrm{~h}$ du CA et le groupe contrôle 1. Au niveau Th, le FSME était diminué pendant le CA ( $p<0.003$ vs. le groupe contrôle 2$), 1 \mathrm{~h}, 6 \mathrm{~h}$ ( $p<0.04$ et $\mathrm{p}<0.01$ vs. le groupe contrôle 1). Au niveau Lo, le FSME n'était pas détectable dans le groupe CA et il était diminué dans les groupes mesurés à $1 \mathrm{~h}$ $(\mathrm{p}<0.003)$ et $6 \mathrm{~h}(\mathrm{p}<0.003)$. Il n'y avait pas de différence entre le groupe mesuré à $24 \mathrm{~h}$ et le groupe contrôle I à tous les niveaux de la moelle épinière. Conclusions: Cette étude démontre qu'il existe une période d'hypoperfusion post-ischémique retardée, d'une duré de 6 heures après le CA au niveau de la substance blanche et de la substance grise de la moelle épinière Th et Lo. Il est possible que ce phénomène ait une influence importante sur le sort du tissus nerveux à la limite de la viabilité suite à une lésion ischémique.
\end{abstract}

Can. J. Neurol. Sci. 1995; 22: 202-207

Paraplegia, secondary to ischemic myelopathy, can follow surgical correction of aortic diseases such as coarctation, atherosclerotic aneurysms, dissection and traumatic rupture. The events occurring after the ischemic period, during the reperfusion phase, have been extensively studied and this research has provided convincing arguments that tissue damage may result in part from postischemic events. ${ }^{1-4}$

Deteriorating stroke is a well-known phenomenon which may affect up to $33 \%$ of stroke victims. It occurs when an ischemic or hemorrhagic insult to the brain is associated to a continued loss of neurological function. Interestingly, a similar phenomenon has been described for the spinal cord, both in the animal model ${ }^{5}$ and in the human. ${ }^{6}$ Known as "delayed-onset

From the Department of Thoracic and Cardiovascular Surgery (F.F., K.M., S.P., R.K.,T.T., J.A.W.), University of New Mexico, Albuquerque and West Los Angeles V.A. Medical Center and Department of Physiology (O.U.S.), University of California at Los Angeles School of Medicine, Los Angeles.

RECEIVED SEPTEMBER 9, 1994. ACCEPTED IN FINAL FORM MARCH 22, 1995.

Reprint requests to: Fabrizio Follis, M.D., University of New Mexico, Department of Thoracic and Cardiovascular Surgery, 2211 Lomas Boulevard, Albuquerque. New Mexico 87131 U.S.A. 
paraplegia", it is described in one-third to one-half of patients who develop neurological dysfunction of the lower extremities after aortic surgery. In this subset, the deficit appears hours and days after the patient has awakened successfully from surgery without neurological impairment. The cause is poorly understood, and the hypotheses include postoperative hypotension, embolization or thrombosis of anterior spinal artery, breakdown of spinal cord blood-brain barrier integrity, ${ }^{7}$ eicosanoid changes and edema of the gray and white matter. ${ }^{2,8.9}$

Conceivably, fluctuations in regional spinal cord blood flow during the reperfusion period could play a critical role in the final recovery or death of elements of the white and gray matter already damaged by the ischemic insult. In this respect, few studies of spinal cord blood flow changes after aortic crossclamping have been reported in various animal models and occlusion protocols. ${ }^{7,10-15}$ The data indicate significant variations in blood flow in the reperfusion period and could form the basis for such a hypothesis.

In light of these considerations, the experiments presented in this study were directed to describe which changes, if any, occur in the spinal cord blood flow (SCBF) during the reperfusion period, after occlusion of the thoracic aorta and both subclavian arteries for 11 minutes in the rat. The data are compared with existing studies in the literature, and a possible relationship with the phenomenon of delayed paraplegia is discussed.

\section{Methods}

\section{Animal preparation}

Male Sprague-Dawley rats 2-3 months old and weighing 250$300 \mathrm{~g}$ were kept in polycarbonate cages with free access to food and water. Animal care was delivered according to the "Principles of Laboratory Animal Care" and the "Guide for the care and use of Laboratory Animals" (NIH Publication No. 86-23, 1985). The animal was fasted overnight, weighed and then placed in a glass chamber with a continuous flow of $2.5 \%$ halothane until response to pinprick was absent. Then the animal's trachea was intubated with a 14\# gauge catheter $(7 \mathrm{~cm}$ long and $2.1 \mathrm{~mm}$ outer diameter) using a neonatal laryngoscope with a Miller 0 blade modified to a width of $7-8 \mathrm{~mm}$. The rat was ventilated with an open circuit volume respirator (Ugo Basile rodent ventilator, Stoelting Instrument Co.) at $80 \mathrm{cycles} / \mathrm{min}$ with halothane $1.3 \%-1.5 \%$ in oxygen. A longitudinal incision was made through the skin in the sternal region. The chest wall was incised from the apex of the manubrium caudad along the left sternal border to the third rib. The thymus was removed and three catheters (PE-10) were placed around the aorta and the origins of the right and left subclavian arteries. The free ends were passed through a $4 \mathrm{~cm}$ tubing (PE-160) creating a snare. Under direct vision the snares were pulled close and secured with a clamp. The vascular occlusion was maintained for 11 minutes, a period of time which has been associated with postoperative paraplegia and histologic injury to the spinal cord in previous studies. ${ }^{16,17}$ Positive end expiratory pressure of $10 \mathrm{~cm}$ of water was instituted during the occlusion. (This is a characteristic of the model: positive pressure ventilation sharply decreases the incidence of pulmonary edema and death on releasing the occlusion). The chest was closed and the snares were released and withdrawn at the end of the occlusion period. Body temperature was monitored by a rectal probe and was maintained at $37^{\circ} \mathrm{C} \pm$ $0.5^{\circ}$ with a thermal pad. Blood flow measurements were performed under anesthesia. In the two groups selected for SCBF measurement in the postperfusion period, the animals were awakened, observed for 6 or 24 hours, depending on the group, and then anesthetized, reintubated and subjected to SCBF measurement. SCBF measurements were carried out under endotracheal anesthesia in all groups, controls for animals who were awakened, extubated and then re-anesthetized were not included.

\section{Experimental protocol}

Fifty-three animals were divided in 6 groups:

The zero hour $(\mathrm{XC}, \mathrm{n}=8)$ group underwent median sternotomy and aortic cross-clamp for a period of 11 minutes. SCBF was measured during cross-clamp. Both subclavian arteries were cannulated for blood pressure monitoring and arterial sampling and thus remained occluded during the procedure.

The one hour ( $1 \mathrm{~h}, \mathrm{n}=9$ ) group underwent median sternotomy and cross-clamp for a period of 11 minutes. The animals were then allowed to stabilize for one hour, under anesthesia, while mechanically ventilated. At the end of this period SCBF was measured. Both femoral arteries were used for blood pressure monitoring and arterial sampling.

The six hour ( $6 \mathrm{~h}, \mathrm{n}=9$ ) group underwent median sternotomy and vascular occlusion for a period of 11 minutes. Then the animal was awakened and extubated. It was allowed to recover for approximately six hours then re-intubated and mechanically ventilated and SCBF was measured using the same vascular access as in group $1 \mathrm{~h}$.

The twenty-four hour ( $24 \mathrm{~h}, \mathrm{n}=11)$ group underwent median sternotomy and vascular occlusion as described above. The animals were allowed to recover for 24 hours then anesthetized with halothane, intubated and mechanically ventilated. SCBF was measured in the same fashion as $1 \mathrm{~h}$ and $6 \mathrm{~h}$ groups.

Two sham operated groups were added to the study: the first one (Sham 1, $\mathrm{n}=8$ ) underwent median sternotomy, dissection of the vessels and placement of the tourniquets but did not have cross-clamp. Femoral arteries were used for blood pressure monitoring and blood sampling as in groups $1 \mathrm{~h}, 6 \mathrm{~h}, 24 \mathrm{~h}$.

The second group (Sham 2, $n=8$ ) underwent median sternotomy and placement of the tourniquets but did not have crossclamp. Subclavian arteries were used for blood pressure monitoring and blood sampling as in group XC.

\section{Measurement of spinal cord blood flow (SCBF)}

This variable was measured by a tracer washout technique employing the iodo- ${ }^{14} \mathrm{C}$-antipyrine (LAP) method. ${ }^{18}$ Bilateral cannulation of both femoral veins was performed in all animals with silastic catheters for IAP and $\mathrm{KCl}$ injections. Depending on the study group both femoral arteries or subclavian arteries were cannulated in order to monitor blood pressure and to obtain blood samples. A $0.3 \mathrm{ml}$ sample of blood was obtained to measure $\mathrm{PaCO}_{2}, \mathrm{PaO}_{2}$ and $\mathrm{pH}$ in a Radiometer ABL 30 Blood Gas Machine. Immediately after, an infusion of ${ }^{14} \mathrm{C}$-IAP was started. Infusate volume was $0.6 \mathrm{ml}$, dose $100-125 \mu \mathrm{Ci} / \mathrm{kg}$ body weight and infusion period 30 seconds. Arterial blood samples $(20 \mu \mathrm{l})$ were obtained every 3 seconds from a free flowing arterial catheter until cardiac arrest and shortly thereafter. At the end of IAP infusion, circulation was arrested by an i.v. pulse of euthanasia solution of $0.8 \mathrm{ml}$ of $3 \mathrm{M} \mathrm{KCl}$. The exact time of cardiac arrest was determined from a continuous record of arterial blood pressure obtained on a polygraph; the samples obtained after cardiac arrest were discarded, the longest possible interval between sampling and cardiac arrest was 2 seconds. Following this, samples (approximately $1 \mathrm{~cm}$ ) of cervical, thoracic and the entire 
lumbosacral cord were removed and flash frozen in methylbutane chilled to $-70^{\circ} \mathrm{C}$. They were then transferred to a cryostat and embedded in OCT compound for later sectioning.

The various segments of spinal cord to be studied were sectioned in a cryostat in $20 \mu \mathrm{m}$ thick slices, at 400 micron intervals, then mounted on glass slides and heat dried on a hot plate at $60^{\circ} \mathrm{C}$ for at least 5 minutes. These dried sections were then exposed to Kodak NMC film for four weeks, along with 8 polymethyl-methacrylate ${ }^{14} \mathrm{C}$ standards of known radioactivity. After exposure, the films were developed on a Kodak XO-Mat processor. Optical density induced in the film by the slides and standards was quantified with a scanning microscope densitometer. Regional spinal cord blood flow ( $\mathrm{rBF}$ ) was calculated from the values of blood radioactivity in the samples collected during the last 30 seconds of the experiment (during IAP infusion). IAP concentration as a function of time was introduced in the operational equation described by Reivich et al. ${ }^{19}$ that, when solved for a series of incremental values of $\mathrm{rBF}$, yielded a table relating blood flow to tissue radioactivity. This table permitted calculation of rBF from the microdensitometric data obtained from the autoradiographs.

\section{Statistical analysis}

The significance of comparisons between controls and postischemic groups was analyzed by the Dunnett test for multiple comparisons, after analysis of variance.

\section{RESULTS}

\section{Physiologic variables}

Analysis of variance between groups for weight, temperature at cross-clamp, arterial blood $\mathrm{pH}, \mathrm{pCO}_{2}, \mathrm{pO}_{2}$ and mean arterial blood pressure during SCBF measurements did not disclose differences except for the $\mathrm{pH}$ in the $1 \mathrm{~h}$ group which was significantly lower $(\mathrm{P}<0.05)$ than Sham 1, Sham 2, XC and $24 \mathrm{~h}$ groups (Table 1).

\section{Spinal cord blood flow (SCBF)}

Three analyses were performed on the data. First, for each segment (cervical, thoracic and lumbar) SCBF was measured in six regions, three in the white matter (ventral column, lateral column and dorsal column), and three in the gray matter (ventral horn, dorsal horn $\mathrm{I}$ and dorsal horn 2 ). In the cervical segment, analysis of variance between blood flows of groups 1 h, 6 h, 24 $h$ and Sham 1 showed no statistical difference among groups in the white (WM) or gray matter (GM). In the thoracic segment, two regions significantly different on ANOVA, thoracic ventral column (TVC) and thoracic lateral column (TLC), were tested against Sham I with the Dunnett test: for TLC, blood flow for the $6 \mathrm{~h}$ group was significantly less than Sham 1 (Table 2). Finally, in the lumbar segment the Dunnett test on all the regions was initially different on ANOVA. A follow-up Dunnett test showed that the blood flow of the $1 \mathrm{~h}$ group was less than Sham 1 in the lumbar ventral column (LVC), lumbar lateral column (LLC) and lumbar dorsal horn 2 (LDH2) (Table 3).

The data from each region were then pooled in order to obtain an average value of SCBF for white and gray matter for each segment of the spinal cord. A Dunnett test was performed and showed that in the cervical cord, SCBF was reduced in XC group in WM and GM, and in the $6 \mathrm{~h}$ group in GM. In the thoracic cord, SCBF was reduced in XC group in WM and GM, and in the $6 \mathrm{~h}$ group in WM and in GM. In the lumbar cord, SCBF was not detectable in XC group in both WM and GM, and reduced in $1 \mathrm{~h}$ in WM and in GM, and in $6 \mathrm{~h}$ in WM and in GM (Figure).

Finally, the pooled data from groups $1 \mathrm{~h}, 6 \mathrm{~h}$ and $24 \mathrm{~h}$ were analyzed by analysis of variance to study the relationship between blood flow and time in the reperfusion period in the WM and GM of each spinal cord segment. The analysis did not show any significant relationship between blood flow and time in the cervical white and gray, and a marginal relationship in the

Table 1: Physiologic Variables in Each Experimental Group.

\begin{tabular}{|c|c|c|c|c|c|c|}
\hline Group & wt (g) & $\mathrm{T}\left({ }^{\circ} \mathrm{C}\right)$ & pH & $\mathrm{pCO}_{2}$ & $\mathrm{pO}_{2}$ & МАВР \\
\hline Sham 1 & $267.0 \pm 5.23$ & $37.5 \pm 0.19$ & $7.33 \pm 0.013$ & $40.6 \pm 1.65$ & $331.6 \pm 60.6$ & $93.7 \pm 7.39$ \\
\hline Sham 2 & $272.8 \pm 7.29$ & $36.5 \pm 0.24$ & $7.38 \pm 0.015$ & $34.6 \pm 1.30$ & $363.6 \pm 34.9$ & $101.9 \pm 5.20$ \\
\hline $\mathrm{XC}$ & $277.3 \pm 7.29$ & $36.6 \pm 0.28$ & $7.35 \pm 0.012$ & $37.5 \pm 1.46$ & $346.1 \pm 29.8$ & $120.7 \pm 5.07$ \\
\hline $\mathrm{l} \mathrm{h}$ & $264.6 \pm 7.05$ & $36.9 \pm 0.26$ & $7.22 \pm 0.040^{\S}$ & $38.3 \pm 2.25$ & $369.8 \pm 36.6$ & $89.4 \pm 13.77$ \\
\hline $6 \mathrm{~h}$ & $281.1 \pm 3.45$ & $36.8 \pm 0.25$ & $7.29 \pm 0.014$ & $35.8 \pm 1.47$ & $379.9 \pm 13.8$ & $98.5 \pm 7.02$ \\
\hline $24 \mathrm{~h}$ & $272.2 \pm 5.82$ & $36.8 \pm 0.25$ & $7.35 \pm 0.018$ & $35.9 \pm 1.45$ & $379.4 \pm 35.8$ & $106.5 \pm 4.21$ \\
\hline
\end{tabular}

Values are mean \pm s.e.; $\S=\mathrm{P}<0.05$ vs. Sham 1 , Sham $2, \mathrm{XC}$ and 24 h by ANOVA.

Table 2: Spinal cord blood flow $\left(\mathrm{ml}^{*} 100 \mathrm{~g}^{-1} * \mathrm{~min}^{-1}\right)$ in the thoracic cord in three regions of white and gray matter'; $\S=\mathrm{P}<0.05$ by the Dunnett test and $\mathscr{T}=\mathrm{P}<0.05$ by two sample $\mathrm{t}$-test between $\mathrm{XC}$ and Sham 2 .

\begin{tabular}{|c|c|c|c|c|c|c|}
\hline Group & TVC & TLC & TDC & TVH & TDH1 & TDH2 \\
\hline Sham 1 & $33.1 \pm 3.0$ & $33.3 \pm 2.9$ & $37.4 \pm 3.7$ & $100.9 \pm 16.8$ & $113.4 \pm 21.7$ & $73.4 \pm 11.8$ \\
\hline Sham 2 & $35.3 \pm 2.1$ & $36.0 \pm 2.6$ & $37.7 \pm 2.6$ & $95.5 \pm 10.6$ & $106.0 \pm 10.9$ & $73.8 \pm 6.4$ \\
\hline $\mathrm{XC}$ & $5.28 \pm 0.7 \rrbracket$ & $6.51 \pm 0.71$ & $6.1 \pm 0.7^{4}$ & $10.9 \pm 1.7 \pi$ & $11.6 \pm 2.09$ & $11.5 \pm 1.1^{\mathrm{g}}$ \\
\hline $1 \mathrm{~h}$ & $24.1 \pm 3.3$ & $23.9 \pm 2.5$ & $26.0 \pm 2.6$ & $60.8 \pm 7.0$ & $69.9 \pm 9.0$ & $45.0 \pm 3.7$ \\
\hline $6 \mathrm{~h}$ & $23.7 \pm 2.0$ & $21.2 \pm 1.9^{8}$ & $24.3 \pm 2.0$ & $60.6 \pm 5.7$ & $63.1 \pm 6.2$ & $47.7 \pm 4.2$ \\
\hline $24 \mathrm{~h}$ & $34.4 \pm 4.5$ & $35.6 \pm 5.3$ & $35.7 \pm 4.6$ & $93.7 \pm 13.0$ & $97.6 \pm 13.3$ & $95.2 \pm 8.3$ \\
\hline
\end{tabular}

1 thoracic ventral column (TVC), thoracic lateral column (TLC), thoracic dorsal column (TDC), thoracic ventral horn (TVH), thoracic dorsal horn 1 (TDH1), thoracic dorsal horn 2 (TDH2). 
Table 3: Spinal cord blood flow $\left(\mathrm{ml} * 100 \mathrm{~g}^{-1 *} \mathrm{~min}^{-1}\right)$ in the lumbar cord in three regions of white and gray matter $; \S=\mathrm{P}<0.05$ by the Dunnett test.

\begin{tabular}{lccrrrr}
\hline Group & LVC & LLC & LDC & LVH & LDH1 \\
\hline Sham 1 & $40.9 \pm 2.7$ & $44.2 \pm 3.4$ & $46.8 \pm 2.6$ & $95.0 \pm 7.1$ & $104.9 \pm 8.2$ & $88.9 \pm 5.3$ \\
Sham 2 & $47.3 \pm 4.3$ & $50.9 \pm 6.2$ & $43.3 \pm 4.4$ & $113.8 \pm 14.7$ & $123.9 \pm 16.4$ & $97.2 \pm 10.2$ \\
XC & & & & & & \\
$1 \mathrm{~h}$ & $\mathbf{2 5 . 5} \pm \mathbf{2 . 5}$ & $\mathbf{2 3 . 6} \pm \mathbf{3 . 3}$ & $22.3 \pm 3.0$ & $59.1 \pm 8.0$ & $61.6 \pm 9.0$ & $\mathbf{4 7 . 6 \pm 6 . 1}$ \\
$6 \mathrm{~h}$ & $32.9 \pm 5.5$ & $30.4 \pm 5.4$ & $32.2 \pm 6.1$ & $75.0 \pm 17.8$ & $\mathbf{7 8 . 8} \pm 18.0$ & $60.8 \pm 11.5$ \\
$\mathbf{2 4} \mathbf{h}$ & $48.9 \pm 5.0$ & $56.6 \pm 4.6$ & $61.7 \pm 14.6$ & $132.5 \pm 12.5$ & $141.3 \pm 12.2$ & $112.7 \pm 11.6$ \\
\hline
\end{tabular}

${ }^{2}$ lumbar ventral column (LVC), lumbar lateral column (LLC), lumbar dorsal column (LDC), lumbar ventral horn (LVH), lumbar dorsal horn 1 (LDH1), lumbar dorsal horn $2(\mathrm{LDH} 2)$.

thoracic white and gray, but disclosed a significant relationship in the lumbar white and gray $\left(P=0.001\right.$ with $r^{2}=0.41$ and $P=$ 0.001 with $r^{2}=0.42$, respectively).

\section{Discussion}

Our study showed that during vascular occlusion of the descending thoracic aorta and both subclavian arteries in the rat, SCBF decreased in the cervical and thoracic cords, and was undetectable in the lumbar cord. In the reperfusion period, SCBF was significantly depressed at $1 \mathrm{~h}$ and $6 \mathrm{~h}$ measurements in both the WM and GM of the thoracic and lumbar cords. It returned to control values by $24 \mathrm{~h}$. Further analysis in six areas of WM and GM identified selected zones in the thoracic and lumbar cords of significantly decreased blood flow while the remaining zones showed a trend ( $P$ between 0.06 and 0.1 ) to have decreased blood flow which did not reach statistical significance, probably because of the limited number of observations. Both during aortic occlusion and in the reperfusion period the most striking changes in SCBF were seen in the lumbar cord. This correlates well with pathologic findings in the lumbar cord of animal models ${ }^{17.20}$ and of human autopsies ${ }^{21}$ and confirms that the lumbar segment is at highest risk of neurologic injury during aortic cross-clamping.

The choice of the methodology for SCBF measurement and of the animal model are two important issues and deserve to be discussed in more depth. Separation of gray and white matter blood flow in the different segments of the spinal cord is essential for an understanding of normal SCBF and its changes in pathological states. Among the methodologies available, the ${ }^{14} \mathrm{C}$ autoradiographic technique provides the best resolution with a spatial accuracy of 10 lines $/ \mathrm{mm}$ : blood flow can be measured in discrete zones of the whole cross-sectional area of the cord. The method, however, requires that the animal be sacrificed at the time of measurement; therefore, for the study of sequential changes, groups of animals are needed at varying intervals. ${ }^{22}$ In addition, the technique precludes perfusion fixation of the animal just before death, and to that end, performance of histological studies. A further limitation resides in the high cost of the radioactive compound in animals of large size, confining this technique to small species.

The rat model of ischemic paraplegia used in this investigation has been described by LeMay et al. ${ }^{16}$ and fully characterized by our group. ${ }^{17}$ It provides a rich neurologic repertoire of the lower extremities and a close similarity with the blood supply of the human spinal cord. ${ }^{23}$ The model requires occlusion of both subclavian arteries with consequent reduction in

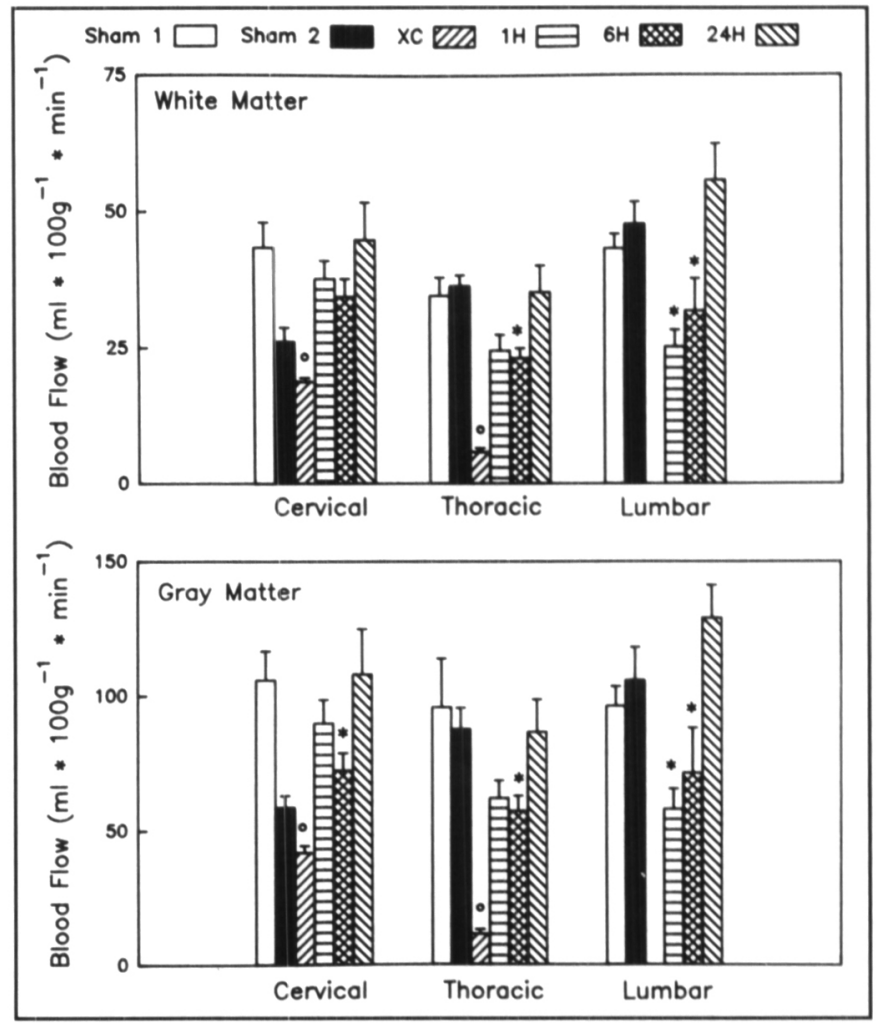

Figure: Average values of spinal cord blood flow in the white and gray matter of cervical, thoracic and lambar cord. $*=P<0.05$ is. Sham 1. $=P<0.05$ vs. Sham 2 .

cervical blood flow; therefore, in this study, the XC group could not be compared with the Sham 1 and a second control (Sham 2) with occlusion of both subclavian arteries only, was needed. Conversely, an appropriate control group for animals who were awakened, extubated and then re-anesthetized for SCBF measurement, although desirable, was not included in the protocol. The physiologic variables (weight, temperature at cross-clamp, arterial blood $\mathrm{pH}, \mathrm{pCO}_{2}, \mathrm{pO}_{2}$ and mean arterial blood pressure during SCBF measurements) were controlled during the experiment, with the exception of the $\mathrm{pH}$ of $1 \mathrm{~h}$ group which was significantly lower (Table 1). We believe this phenomenon is likely due to the severe metabolic acidosis following release of vascular occlusion and should not be considered an important variable to influence blood flow data. Finally, functional outcome could not be studied because of the acute nature of this experiment. 
Previous measurements of SCBF during and after aortic cross-clamping are reported in the literature in various animal models. Studies carried out in the dog, ${ }^{10.11}$ in the swine ${ }^{12}$ and in the baboon ${ }^{13}$ employed the microsphere technique which allows sequential measurements but does not discriminate WM from GM. ${ }^{24}$ In addition, SCBF was used to evaluate intraoperative interventions to decrease the incidence of paraplegia, and consequently the measurements were primarily directed to the crossclamping period. As expected, all studies showed that blood flow becomes progressively less down the length of the spinal cord during aortic occlusion. In the reperfusion period, an hyperemic response was seen within $30^{12}$ to 60 minutes, ${ }^{13}$ and it was still present in the only study where a measurement was performed $24 \mathrm{~h}$ after release of aortic cross-clamp. ${ }^{14} \mathrm{~A}$ more complete study of SCBF in the reperfusion period was reported by Jacobs et al. ${ }^{7}$ in the rabbit model. This investigation employed the same autoradiographic technique used in our study with measurements at $0.5,4,12$ and $24 \mathrm{~h}$. In all regions, SCBF was not different from control levels after 30 minutes of reperfusion; at $4 \mathrm{~h}$ SCBF was reduced in the ventral and intermediate white matter of the lumbar cord. Interestingly, in the same regions, SCBF was elevated vs. control at $12 \mathrm{~h}$, and $24 \mathrm{~h}$ both in WM and GM. Finally, Chavko et al., ${ }^{15}$ in the same rabbit model and with the same technique, found an hyperemic response 30 minutes after ischemia and no difference from controls four days later.

In an attempt to interpret the conflicting data reported above, ours included, we can speculate that SCBF in the reperfusion period varies according to the peculiarities of spinal cord blood supply of each animal model, the different type and duration of occlusion, the techniques and the sampling times of spinal cord blood flow measurements. However, without doubt, SCBF is not normal in the first $24 \mathrm{~h}$ after an ischemic insult and can be characterized by periods of initial and delayed hyperemic response and of delayed hypoperfusion, before the return to baseline blood flow values. This is similar to what has been described in models of cerebral ischemia ${ }^{1,25}$ and in human subjects after stroke. ${ }^{26}$ The possible implications of this phenomenon are broad and relink to the premises of this study.

A critical interval measured in hours may exist after a period of ischemia (especially after moderate degree of ischemia) characterized by three hypothetical conditions: neural function is suspended but the cells remain viable with potential for full recovery. Alternatively, neural function is restored but the neural elements are still recovering from the ischemic insult, therefore they are in a precarious condition. Finally, some cells have died and others are in a borderline state susceptible to further injury. This time window, also termed "the maturation phenomenon" may be followed by complete recovery, the new onset of neurologic deficit (delayed onset paraplegia) or further neurologic deterioration (e.g., deteriorating stroke). In the latter two circumstances, we have to assume that the ischemic episode established conditions that could produce irreversible damage during the reperfusion period. This state has been identified in an abnormally high intracellular calcium which initiates a cascade of celluar events. ${ }^{27}$ Among them, production of vasospastic prostagandins $^{28}$ and vascular smooth muscle contraction secondary to calcium influx, may be responsible for the defect in the microcirculation observed after cerebral and spinal cord ischemia. Such perfusion abnormalities, in turn, could produce more ischemia and perpetuate the injury. The present study confirmed the presence of an abnormal microcirculation after spinal cord ischemia and fully defined its extension in the segments of spinal cord and the various areas of the WM and GM. Correlation with functional outcomes was not possible. Therefore, a relationship with the clinical syndromes above mentioned remains speculative. However, we believe this study forms the basis for future investigations employing serial measurements in the same animals (e.g., hydrogen blood flow measurement of one area of the lumbar cord) and allowing assessment of functional outcomes and histologic changes, in order to correlate, in the same animal, different degrees of ischemic injury with SCBF in the reperfusion period and neurologic, histologic outcomes.

In summary, the following considerations can be made: 1) The present study has described a period of delayed hypoperfusion in the WM and GM of the thoracic and lumbar cord lasting six hours after occlusion of the descending thoracic aorta and both subclavian arteries for 11 minutes in the rat model; 2) Review of previous reports in the literature allow us to conclude that SCBF is not normal during reperfusion after aortic crossclamping and significant variations above or below control values do occur; 3 ) More studies are needed to elucidate the post-ischemic phase and to correlate the variations of SCBF with the neurological and pathological outcomes.

\section{ACKNOWLEDGEMENTS}

The authors thank Clifford Qualls, Ph.D. (Department of Mathematics and Statistics at the University of New Mexico) for assistance in the statistical evaluation of data and Deborah L. Heuser for technical assistance; supported in part by a Grant-in-Aid from the American Heart Association with funds contributed in part by the New Mexico Affiliate.

\section{REFERENCES}

1. Watson N. Paraplegia following cardiovascular surgery. Paraplegia 1979; 17: 294-297.

2. Hallenbeck JM, Furlow TW Jr. Prostaglandin I-2 and indomethacin prevent impairment of post-ischemic brain reperfusion in the dog. Stroke 1979; 10: 629-637.

3. Ito U, Spatz M, Walker JT Jr, Klatzo 1. Experimental cerebral ischemia in Mongolian gerbils. Acta Neuropathol (Berl) 1975; 32: 209-223

4. Pulsinelli WA, Brierley JB, Plum F. Temporal profile of neuronal damage in a model of transient forebrain ischemia. Ann Neurol 1982; 11: 491-498.

5. Moore WM Jr, Hollier LH. The influence of severity of spinal cord ischemia in the etiology of delayed-onset paraplegia. Ann Surg 1991; 213: 427-432.

6. Svensson LG, Crawford ES, Hess KR, Coselli JS, Safi HJ. Experience with 1509 patients undergoing thoracoabdominal aortic operations. J Vasc Surg 1993; 17: 357-370.

7. Jacobs TP, Kempski O, McKinley D, et al. Blood flow and vascular permeability during motor dysfunction in a rabbit model of spinal cord ischemia. Stroke 1992; 23: 367-373.

8. Jacobs TP, Shohami E, Baze W, et al. Deteriorating stroke model: histopathology, edema and eicosanoid changes following spinal cord ischemia in rabbits. Stroke 1987; 18: 741-750.

9. Feuerstein G. Eicosanoids in deteriorating stroke: review of studies on the rabbit spinal cord ischemia and reperfusion model. Ann NY Acad Sci 1989; 559: 313-322.

10. Elmore JR, Gloviczki P, Harper CM Jr, et al. Spinal cord injury in experimental thoracic aortic occlusion: investigation of combined methods of protection. J Vasc Surg 1992; 15: 789-799.

11. Elmore JR, Gloviczki P, Harper CM, Pairolero PC. Failure of motor evoked potentials to predict neurologic outcome in experimental thoracic aortic occlusion. J Vasc Surg 1991; 14: 131-139.

12. Qayumi AK, Janusz MT, Jamieson WRE, Lyster DM. Pharmacologic interventions for prevention of spinal cord injury caused by aortic cross-clamping. J Thorac Cardiovasc Surg 1992; 104: 256-261. 
13. Svensson LG, von Ritter CM, Groeneveld HT. Cross-clamping of the thoracic aorta: influence of aortic shunts, laminectomy, papaverine, calcium channel blocker, allopurinol and superoxide dismutase on spinal cord blood flow and paraplegia in baboons. Ann Surg 1986; 204: 38-47.

14. Reuter DG, Tacker WA Jr, Badylak SF, Voorhees WD III, Konrad PE. Correlation of motor-evoked potential response to ischemic spinal cord damage. J Thorac Cardiovasc Surg 1992; 104: 262-272.

15. Chavko M, Kalincakova K, Kluchova D, Nemoto E. Blood flow and electrolytes in spinal cord ischemia. Exp Neurol 1991; 112: 299-303.

16. LeMay DR, Neal S, Zelenock GB, D'Alecy LG. Paraplegia in the rat induced by aortic cross-clamping: model characterization and glucose exacerbation of neurologic deficit. J Vasc Surg 1987; 6: 383-390.

17. Follis F, Scremin OU, Blisard KS, et al. Selective vulnerability of white matter during spinal cord ischemia. J Cereb Blood Flow Metab 1993; 13: 170-178.

18. Sakurada O, Kennedy C, Jehle J, et al. Measurement of local cerebral blood flow with iodo-[14C]-antipyrine. Am J Physiol 1978; 234: H59-H66.

19. Reivich M, Jehle J, Sokoloff L, Kety SS. Measurement of regional cerebral blood flow with antipyrine-[14C] in awake cats. J Appl Physiol 1969; 27: 296-300.
20. DeGirolami U, Zivin JA. Neuropathology and experimental spinal cord ischemia in the rabbit. J Neuropathol Exp Neurol 1982; 41: 129-149.

21. Kim SW, Kim RC, Choi BH, Gordon SK. Non-traumatic ischaemic myelopathy: a review of 25 cases. Paraplegia 1988; 26: $262-272$.

22. Sandler AN, Tator $\mathrm{CH}$. Review of the measurement of normal spinal cord blood flow. Brain Res 1976; 118 : 181-198.

23. Tveten L. Spinal cord vascularity: IV. The spinal cord arteries in the rat. Acta Radiol (Diagn) 1976; 17: 385-398.

24. Heymann MA, Payne BD, Hoffman JIE, Rudolph AM. Blood flow measurements with radionuclide-labeled particles. Prog Cardiovasc Dis 1977; 20 : 55-79.

25. Levy DE, Van Uitert RL, Pike CL. Delayed postischemic hypoperfusion: a potentially damaging consequence of stroke. Neurology 1979; 29: 1245-1252.

26. Olsen TS, Larsen B, Skriver EB, et al. Focal cerebral hyperemia in acute stroke: incidence, pathophysiology and clinical significance. Stroke 1981; 12: 598-607.

27. Siesjö BK. Cell damage in the brain: a speculative synthesis. J Cereb Blood Flow Metab 1981; 1: 155.

28. Van Nueten JM, Vanhoutte PM. Improvement of tissue perfusion with inhibitors of calcium ion influx. Biochem Pharmacol 1980: 29: 479 . 